\title{
Ecomorphology of radii in Canidae: Application to fragmentary fossils from Plio-Pleistocene hominin assemblages
}

Carlo Meloro and Julien Louys

Acta Palaeontologica Polonica 60 (4), 2015: 795-806 doi:http://dx.doi.org/10.4202/app.00080.2014

Fragmentary long bone material from fossil Carnivora is rarely considered to support palaeoenvironmental reconstructions. Here, we use morphometry of the radius in extant carnivorans of the dog family (Canidae) to reconstruct the palaeobiology of extinct canids from Olduvai Gorge, Tanzania (Bed I and II) and Koobi Fora, Kenya. We use radius morphometrics to predict adaptation to prey size and introduce a new method for quantifying canid habitat adaptations based on the geographic distributions of the extant species sampled. Linear Discriminant Function Analyses (DFA) and cluster neighbour-joining algorithms are employed to investigate radial morphometrics as described by 29 linear measurements. Results of our analyses suggest that a phylogenetic signal is present in radial morphometrics, even if it does not allow us to accurately discriminate among genera. A binary prey size categorisation of "small-medium" versus "large" prey can be more accurately predicted than a habitat categorisation scheme (Open, Mixed, Closed). The East African fossil specimens examined show morphometric affinities with the golden jackal (Canis aureus) and coyote (Canis latrans) and are likely attributable to the genus Canis. Fragmentary fossil specimens from Olduvai Gorge are predicted as habitat generalists (Open for Bed I and Mixed for Bed II) adapted for hunting small-medium prey, whereas the specimen from Koobi Fora was predicted as inhabiting mixed habitats and adapted for killing large prey. This study supports the inclusion of fossil Canidae in palaeoecological analyses attempting to clarify the palaeoenvironment of early hominin fossil sites.

Key words: Mammalia, Canidae, Canis, habitat adaptation, palaeoenvironment, predation, Plio-Pleistocene, Africa, Kenya.

Carlo Meloro [C.Meloro@ljmu.ac.uk], Research Centre in Evolutionary Anthropology and Palaeoecology, School of Natural Sciences and Psychology, Liverpool John Moores University, Byrom Street, Liverpool L3 3AF, UK; Julien Louys [julien.louys@anu.edu.au], Department of Archaeology and Natural History, School of History, Culture and Languages, ANU College of Asia and the Pacific, The Australian National University, ACT 0200, Australia. 
This is an open-access article distributed under the terms of the Creative Commons

Attribution License (for details please see creativecommons.org), which permits unrestricted use, distribution, and reproduction in any medium, provided the original author and source are credited.

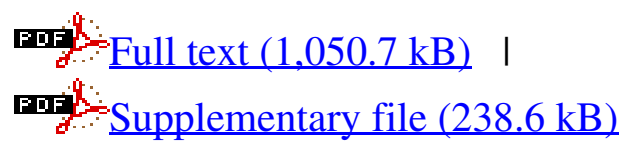

